Both children, a brother and sister, had typical cystinosis, severe rickets, and advanced renal failure. Both had previously been unsuccessfully treated with high doses of vitamin D2, with calcium and phosphorus supplements. We found, in contradistinction to Etches et al., that with our treatment in both cases serum calcium was raised, while phosphorus fell almost to normal level and with little fluctuation. There was clinical improvement, bone pains disappeared in 8 days, and radiological healing was complete in $3 \frac{1}{2}$ months.

Siegfried I. Beer, Ellis VURe, Chaim Krispin, MORDECHAI WARON, and DAVID KOHELET Department of Pediatrics $B$, Assaf Harofeh Hospital, Zerifin, Israel

\section{Variations in height throughout the day}

Sir,

It is well known that stature becomes less as the day progresses, but it is usually considered that gentle traction upwards on the head when measuring height will compensate for this effect. Whitehouse et al. (1974), using this technique, showed an average decrease in stature from 9.30 a.m. to 2 p.m. of only $2 \mathrm{~mm}$ in 19 boys, and from 10 a.m. to 5 p.m. of $4.6 \mathrm{~mm}$ in another group of 11 boys. Strickland and Shearin (1972), using a similar technique, showed a mean difference of $1.54 \mathrm{~cm}$ between the height of 100 children immediately after getting out of bed in the morning and between 4 and 5 p.m. The significance of the difference of heights dependent on time of day of measurement has recently become apparent in a longitudinal growth study. Estimations of the height of a subject undertaken in the latter part of the day using the method described by Tanner et al. (1966) with gentle traction have shown significant differences from those performed in the morning by the same technique and by the same competent observer (who was not influenced by knowledge of previous measurements).

28 boys (age range 7-14 years) have been measured in this way between 6 and 9 p.m. and between 9 a.m. and noon the following morning. Except for 2 subjects for whom the two measurements were the same, the morning height was greater than the evening one by amounts ranging from 0.1 to $1.4 \mathrm{~cm}$ (mean of 0.6 ). The bulk of this change is in the trunk, as expected, and was indicated by similar changes in sitting height to those of total stature.

Eight boys were measured late one evening and repeatedly through the ensuing day. Their measurements are shown in the Figure. The difference between the maximum and minimum heights for any individual is considerable (the maximum always being that on first rising in the morning), ranging from 0.8 to $2.8 \mathrm{~cm}$. A large proportion of the extra early morning height is lost within the first few hours of being mobile during the day. The decline in height is not always continuous throughout the day nor are measurements necessarily identical at

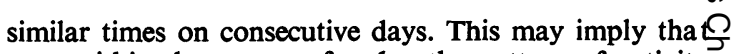
even within the course of a day the pattern of activity may affect stature to a small degree.

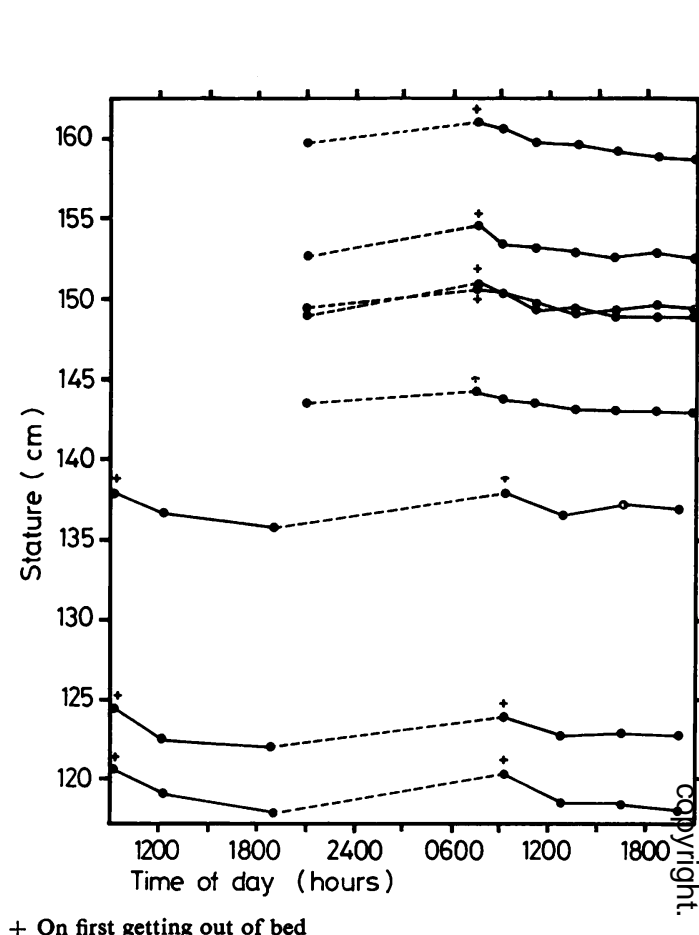

+ On first getting out of bed

Figure Measurement of stature of 8 boys at various times on two consecutive days.

These observations must have implications in the inter pretation of serial height measurements of children. In theory, observations should be undertaken at approxis. mately the same time of day and following a similary pattern of activity, but certainly not immediately aftern getting out of bed. In the clinic these circumstancesifrequently apply, but when this is not the case the 3 . possibility of an error due to this variation, and no: necessarily to accuracy of measurement, should be considered.

\section{J. M. H. BUCKLER? Department of Paediatrics and Child Health, University of Leeds, 27 Blundell Street, Leeds LS1 3ET}

References

Strickland, A. L., and Shearin, R. B. (1972). Diurnal height variation in children. Journal of Pediatrics, 80, 1023-1025

Tanner, J. M., Whitehouse, R. H., and Takaishi, M. (1966). Standards from birth to maturity for height, weight height velocity, and weight velocity: British children 1965 Part I. Archives of Disease in Childhood, 41, 454-471.

Whitehouse, R. H., Tanner, J. M., and Healy, M. J. R.ס (1974). Diurnal variation in stature and sitting height in 12-14 year old boys. Annals of Human Biology, 1, 103-106 